\title{
Therapeutic strategy with artificially-designed i-IncRNA targeting multiple oncogenic microRNAs exhibits effective antitumor activity in diffuse large B-cell lymphoma
}

\author{
Yinghan Su ${ }^{1,2, *}$, Bin Sun ${ }^{2, *}$, Xuejing Lin ${ }^{2, *}$, Xinying Zhao ${ }^{3}$, Weidan $\mathrm{Ji}^{2}$, Miaoxia $\mathrm{He}^{3}$, \\ Haihua Qian' ${ }^{2}$, Xianmin Song ${ }^{3}$, Jianmin Yang ${ }^{3}$, Jianmin Wang ${ }^{3}$, Jie Chen ${ }^{3}$ \\ ${ }^{1}$ School of Life Science, University of Liverpool, Liverpool, L3 4PH, UK \\ ${ }^{2}$ Department of Molecular Oncology, Eastern Hepatobiliary Surgical Hospital \& National Center of Liver Cancer, Second \\ Military Medical University, Shanghai 200438, China \\ ${ }^{3}$ Department of Hematology \& Pathology, Changhai Hospital, Second Military Medical University, Shanghai 200168, China \\ *These authors have contributed equally to this work \\ Correspondence to: Jie Chen, email: chenjiedoctor@163.com \\ Keywords: diffuse large B-cell lymphoma, artificial long non-coding RNA, oncogenic microRNA, xenograft model, therapeutic \\ strategy \\ Received: December 10, 2015 \\ Accepted: April 18, 2016 \\ Published: May 09, 2016
}

\section{ABSTRACT}

In diffuse large B-cell lymphoma (DLBCL), many oncogenic microRNAs (OncomiRs) are highly expressed to promote disease development and progression by inhibiting the expression and function of certain tumor suppressor genes, and these OncomiRs comprise a promising new class of molecular targets for the treatment of DLBCL. However, most current therapeutic studies have focused on a single miRNA, with limited treatment outcomes. In this study, we generated tandem sequences of 10 copies of the complementary binding sequences to 13 OncomiRs and synthesized an interfering long non-coding RNA (i-IncRNA). The highly-expressed i-IncRNA in DLBCL cells would compete with the corresponding mRNAs of OncomiR target genes for binding OncomiRs, thereby effectively consuming a large amount of OncomiRs and protecting many tumor suppressor genes. The in vitro experiments confirmed that the i-IncRNA expression significantly inhibited cell proliferation, induced cell cycle arrest and apoptosis in DLBCL cell lines, mainly through upregulating the expression of PTEN, p27 kip1, TIMP3, RECK and downregulating the expression of p38/MAPK, survivin, CDK4, c-myc. In the established SUDHL-4 xenografts in nude mice, the treatment strategy involving adenovirus-mediated i-IncRNA expression significantly inhibited the growth of DLBCL xenografts. Therefore, this treatment would specifically target the carcinogenic effects of many OncomiRs that are usually expressed in DLBCL and not in normal cells, such a strategy could improve anti-tumor efficacy and safety and may be a good prospect for clinical applications.

\section{INTRODUCTION}

Diffuse large B-cell lymphoma (DLBCL) is one of the most common types of non-Hodgkin's lymphoma (NHL) with poor prognosis. During recent years, optimized stratified treatment regimens based on clinical stage and international prognostic index (IPI) together with post-chemotherapy hematopoietic stem cell transplantation or molecular targeted therapy have been gradually adopted in clinical practice and have provided a focus and direction for advances in DLBCL treatment [1-3]. These comprehensive treatment regimens prolong the remission and disease-free survival of patients with DLBCL, thereby improving the overall treatment outcomes. However, relapse and drug resistance remain the leading causes of death in patients with DLBCL; hence, we must find new treatment strategies to address the shortcomings of the few currently available alternative 
treatment options and poor outcomes of DLBCL treatment and should strive to achieve complete remission or good long-term survival in patients.

Micro-ribonucleic acids (microRNAs; miRNAs) regulate a large number of human genes. miRNAs are small molecules that are present in large numbers, have characteristics of wide distribution and significant effect, and are an integral part of the gene regulatory network $[4,5]$. In 2002, one research group conducted a study of B-cell chronic lymphocytic leukemia and observed a loss of expression of miR-15 and miR-16, thus providing the first evidence of an association between miRNAs and tumors [6]. Subsequently, an increasing number of studies have observed abnormal miRNA expression in many tumors, and this appears to associate closely with the regulation of tumor development and progression $[7,8]$. Therefore, miRNAs have become an important target of targeted cancer therapies. Regarding DLBCL development and progression, many miRNAs are found to directly affect DLBCL differentiation, malignant transformation, and the regulation of sensitivity to chemical drugs, thus affecting the treatment outcomes and prognoses of patients. In particular, miRNAs highly expressed in DLBCL can directly or indirectly inhibit the expression and function of certain tumor suppressor genes, and thus, these miRNAs are also known as oncogenic miRNAs (OncomiRs). Studies have reported that many miRNAs are highly expressed in DLBCL, such as miR-17-5p, miR-18a-5p, miR-19b-3p, miR-20a-5p, miR-21, miR-23a, miR-27a, miR-28-5p, miR-106a-5p, miR-125a/5b, miR-146a, miR-148a, miR-150, miR-155, miR-181a-5p, miR-200c, miR-212, miR-214-5p, miR221/222, miR-324-5p, miR-339-3p, miR-363, miR-487b, miR-513, miR-518a, miR-770-5p, miR-5586-5p, miR10393-3p, NOVELM00203M, etc. [9-11]. Based on the mechanism of miRNA function, the OncomiRs can target a varity of onco-suppressor genes and inhibit their posttranscriptional expression. For example, PTEN (phosphate and tensin homolog) is a tumor suppressor gene, which was regulated by several miRNAs, such as miR-21 [12], miR-155 [13], miR-221/222 [14], and miR-17 92 cluster [15]. In DLBCL, the high-expressed OncomiRs bind to PTEN mRNA and inhibit its expression. Loss of PTEN leads to activation of the PI3K/AKT/mTOR pathway, then promotes the proliferation and progression of DLBCL, and shortens the progression-free survival (PFS) and overall survival (OS) in patients with DLBCL. These miRNAs comprise a promising new class of molecular targets for the treatment of DLBCL. miR-21 is an OncomiR that affects the development and progression of DLBCL, and its expression correlates positively with the tumor cell proliferation index. miR-21 inhibitor interferes with miR21 expression, thereby inhibiting the proliferation and invasion of DLBCL cells and inducing apoptosis [16]. Therefore, miR-21 regulates the malignant biological behaviors of DLBCL, and accordingly, anti-miR-21 approach may become a useful DLBCL treatment strategy. Studies have confirmed that the use of miRNA inhibitors or antisense sequences to block OncomiR expression or inhibit OncomiR function can inhibit the growth of many tumors [17-20].

However, most current therapeutic studies have focused on a single miRNA, with limited treatment outcomes. These unsatisfactory treatment outcomes might occur because miRNAs target many genes in the setting of complex regulatory mechanisms. One miRNA can target many genes, and one target gene might be regulated by many miRNAs. Furthermore, many miRNA molecules are involved in tumor development and progression through the extensive regulation of target gene expression or through effects on many signaling pathways. Therefore, cancer cells can easily regain proliferative activity through alternative pathways. As a result, interventions that target many miRNAs with different or complementary mechanisms and inhibit multiple signaling pathways will be more effective for cancer treatment.

Intracellular miRNAs bind to the messenger RNAs (mRNAs) of target genes with complementary sequences to induce mRNA degradation or inhibit mRNA translation, thereby exerting their role as post-transcriptional regulators of target genes [21]. Based on the mechanisms of miRNA functions, we selected those that are highly expressed in DLBCL, including miR-21, miR-155, miR221/222, miR-125a-5p/125b, and miR-146a/146b-5p, as well as the miR-17-92 family members miR-17, miR$19 \mathrm{a} / 19 \mathrm{~b}$, and miR-20a/20b; subsequently, we generated tandem sequences of 10 copies of the antisense sequences to these miRNA seed sequences and synthesized an interfering long non-coding RNA (i-lncRNA). This i-lncRNA contained multiple repeat sequences capable of binding to the OncomiRs aforementioned; accordingly, the i-lncRNA would compete with the corresponding mRNAs of target genes for OncomiR binding, thereby effectively consuming a large amount of OncomiRs in the cells. This process would interfere with many OncomiRs by protecting the targeted tumor suppressor genes and promoting anti-tumor effects. This treatment strategy would specifically target the carcinogenic effects of many OncomiRs that are usually not expressed in normal cells. Therefore, such a treatment strategy could improve anti-tumor efficacy and safety and is a good prospect for clinical applications.

\section{RESULTS}

\section{Efficiency of adenovirus infection and interaction between i-IncRNA and OncomiRs}

Adenoviruses Ad5F35-i-lncRNA and Ad5F35-EGFP were constructed to express an interfering long non-coding RNA (i-lncRNA) and EGFP, respectively (Figure 1A). All cell lines were infected with Ad5F35-EGFP at MOIs of 
$10,50,100$ and $200 \mathrm{pfu} / \mathrm{cell}$ to count the viral infection efficiency. At an MOI of $100 \mathrm{pfu} / \mathrm{cell}$, the infection efficiencies were $86.33 \%, 91.51 \%, 82.56 \%$, and $78.52 \%$ in the OCI-Ly10, SUDHL-4, DB, and IM-9 cell lines, respectively (Figure 1B). MOIs of $200 \mathrm{pfu} / \mathrm{cell}$ induced more cell death. Therefore, a standard MOI of $100 \mathrm{pfu} / \mathrm{cell}$ was used in the cytological experiments.

Quantitative RT-PCR (qRT-PCR) was performed to detect OncomiR expression in the experimental cells. The expression levels of miR-21, miR-155, miR-221/222, miR-125a-5p/125b, miR-146a/146b-5p, miR-17, miR$19 \mathrm{a} / 19 \mathrm{~b}$, and miR-20a/20b were significantly higher in the OCI-Ly10, SUDHL-4, and DB cells than in the IM-9 cells. Of these OncomiRs, the expression levels of miR21, miR-155, miR-221/222, miR-17, miR-19a/19b, and miR-20a/20b were higher in OCI-Ly10 cells, whereas the expression levels of miR-21, miR-155, miR-125a5p/125b, miR-146a/146b-5p, and miR-17 were higher in SUDHL-4 and DB cells (Figure 1C). The cells were infected with Ad5F35-i-lncRNA at an MOI of $100 \mathrm{pfu} / \mathrm{cell}$ and subjected to qRT-PCR to detect i-lncRNA expression. In accordance with the Ad5F35-EGFP-mediated EGFP expression, i-lncRNA expression was slightly higher in the OCI-Ly10, SUDHL-4, and DB cells than in the IM-9 cells,
A
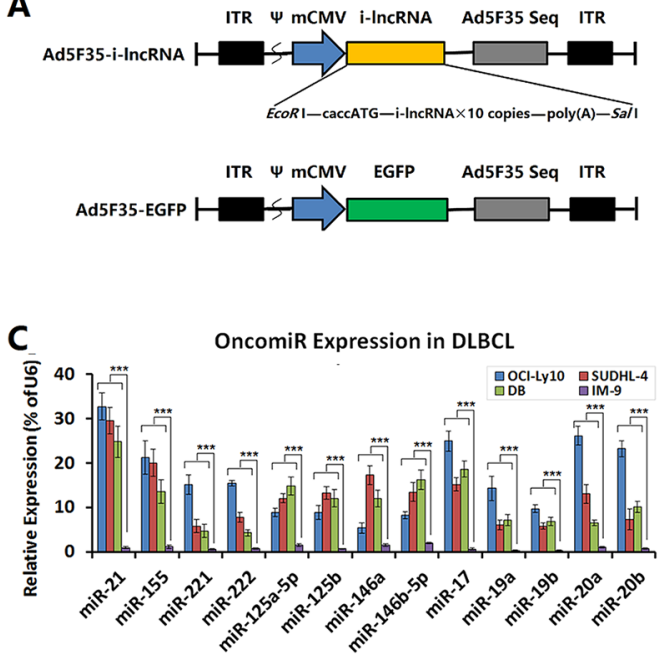

D i-IncRNA Expression

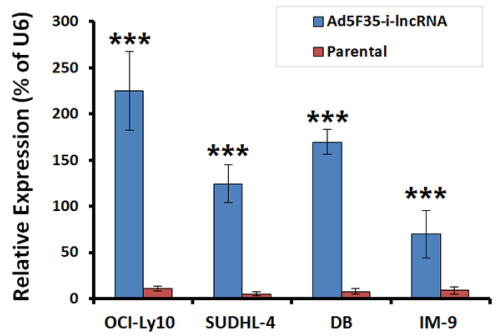

B
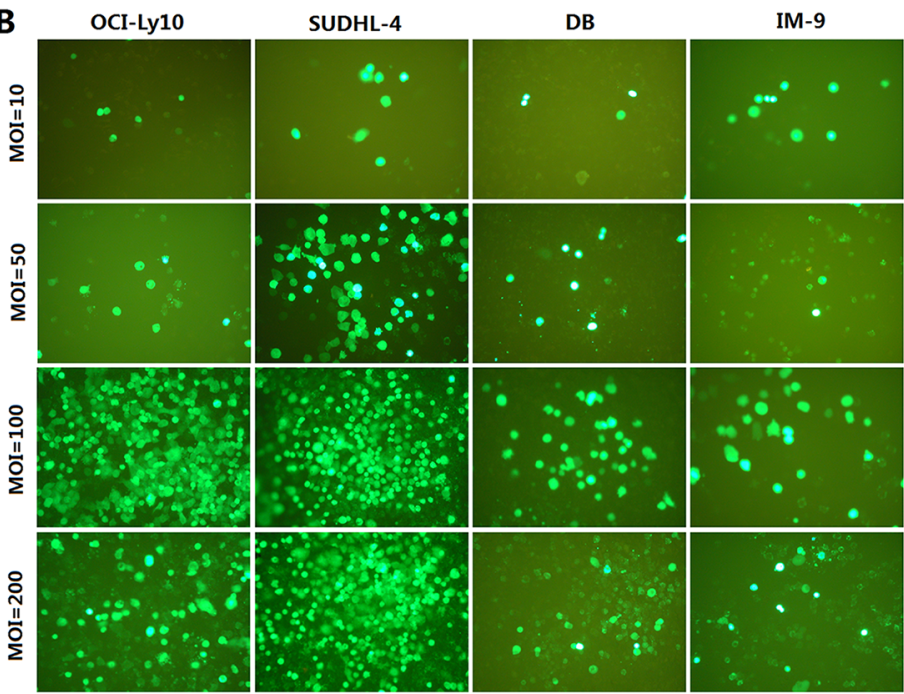

E

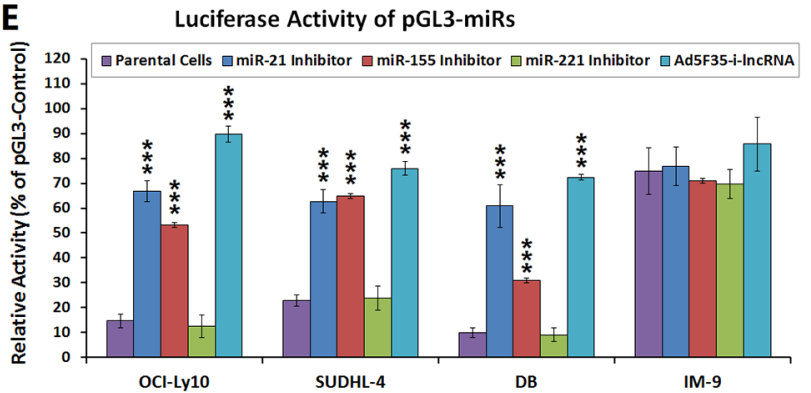

Figure 1: Efficiency of adenovirus infection and expression of OncomiRs and i-IncRNA. A. Schematic diagrams of the adenoviruses, the expression cassette of whole-length encoding sequence of i-lncRNA or the EGFP gene was inserted into the EcoRI + SalI sites of adenovirus E1 region, to generate the recombinant adenovirus Ad5F35-i-lncRNA or Ad5F35-EGFP. ITR: inverted terminal repeats; $\psi$ : adenovirus 5 packaging signal; mCMV: mouse cytomegalovirus promoter. B. DLBCL cell lines (OCI-Ly10, SUDHL-4, DB) and normal human peripheral B cell line (IM-9) were cultured in 96-well plates at a density of $1 \times 10^{4}$ cells $/ 100 \mu \mathrm{L} /$ well for $24 \mathrm{~h}$, then infected with Ad5F35-EGFP at MOIs of 10, 50, 100 and $200 \mathrm{pfu} / \mathrm{cell}$. Another $48 \mathrm{~h}$ later, the percentages of EGFP-positive cells were observed and counted under a fluorescent microscope; original magnification: $200 \times$. C. The aforementioned cell lines were cultured in 6 -well plates at a density of $1 \times 10^{5}$ cells $/ 100 \mu \mathrm{L} /$ well for $48 \mathrm{~h}$, then harvested for isolation of total RNA, which was used to detect the expression levels of the indicated OncomiRs by qRT-PCR; $* * * P<0.001$. D. Cell lines were cultured in 6 -well plates at a density of $1 \times 10^{5}$ cells/100 $\mu \mathrm{L} /$ well for $24 \mathrm{~h}$, then infected with Ad5F35-i-lncRNA at an MOI of $100 \mathrm{pfu} / \mathrm{cell}$. Another $48 \mathrm{~h}$ later, cells were harvested for isolation of total RNA, which was used to detect the expression levels of i-lncRNA by qRT-PCR; *** $P<0.001$ compared with the corresponding parental cells. E. Cell lines were seeded into 24 -well plates at a density of $5 \times 10^{5}$ cells/well and transfected with miRNA inhibitors at a concentration of $100 \mathrm{nmol} / \mathrm{L}$ or infected with Ad5F35-i-lncRNA at MOIs of 10 to $200 \mathrm{pfu} / \mathrm{cell}$. After incubation for $24 \mathrm{~h}$, cells were co-transfected with 200 ng/well of pGL3-miRs together with $20 \mathrm{ng} /$ well of pRL-TK using Lipofectamine 2000. At $48 \mathrm{~h}$ after transfection, cells were harvested and used to detect the relative luciferase activity with the Dual-Luciferase Reporter Assay, normalized with the activity of pGL3-Control in every cell line; $* * * P<0.001$ compared with the corresponding parental cells. 
although this difference was not statistically significant. The uninfected cells exhibited no i-lncRNA expression (Figure 1D).

We confirmed the interactions between the OncomiRs and the complementary binding sequences within i-lncRNA by a luciferase assay. The luciferase activities of pGL3-miRs containing miR-21 and miR-155 binding sites were lower in OCI-Ly10, SUDHL-4 and DB cells than in IM-9 cells, and the inhibitors of miR21 and miR-155 could increase the luciferase levels in DLBCL cells, but the control miR-221 inhibitor did not. The luciferase activities of pGL3-miRs in the Ad5F35-iIncRNA-infected DLBCL cells were markedly increased, but only an unconspicuous upregulation IM-9 cells (Figure 1E), suggesting that the lncRNAi expression could protect the target gene from being inhibited by OncomiRs in DLBCL cells.

\section{Effect of i-IncRNA expression on DLBCL cell proliferation}

Cells were infected with Ad5F35-i-lncRNA and Ad5F35-EGFP at MOIs of 10, 50, 100 and $200 \mathrm{pfu} / \mathrm{cell}$ and subjected to CCK-8 assay to analyze the effect of i-lncRNA expression on cell proliferation. The results showed that Ad5F35-i-lncRNA infection significantly inhibited DLBCL cell proliferation, with a significant decrease in viability observed in OCI-Ly10 and SUDHL-4 cells. At an MOI of 100 $\mathrm{pfu} /$ cell, the viabilities of OCI-Ly10 and SUDHL-4 cells were reduced to less than $50 \%$, and the viability of DB cells was reduced to less than $70 \%$. The control adenovirus Ad5F35EGFP had no significant inhibitory effect on proliferation in any cell line when MOIs were equal to and below $100 \mathrm{pfu} /$ cell, but the viability of IM-9 cells was decreased significantly at an MOI of $200 \mathrm{pfu} / \mathrm{cell}$ (Figure 2A). At an MOI of
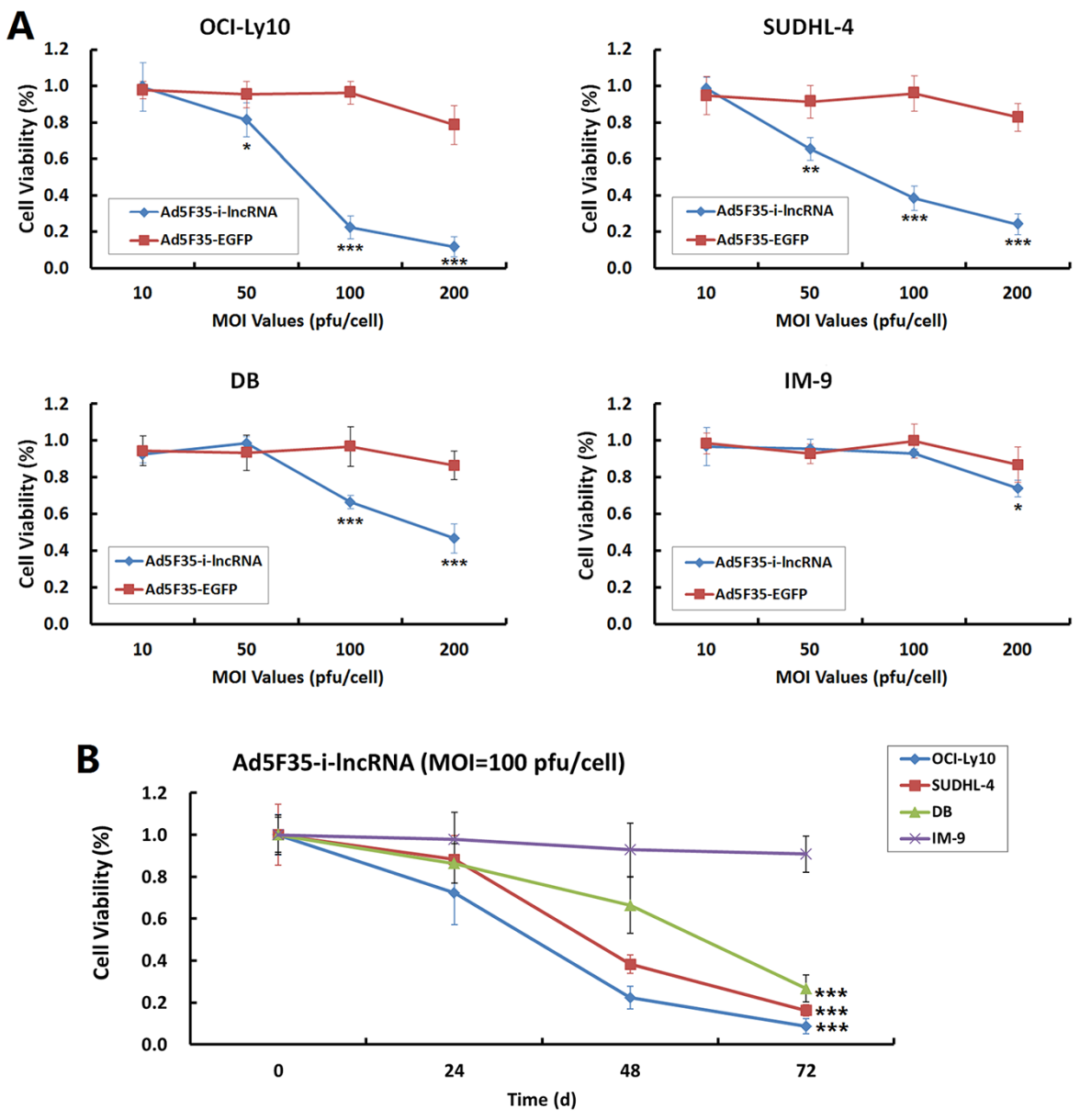

Figure 2: Inhibitory effect of i-IncRNA on cell proliferation. A. The four cell lines were planted in 96-well plates at a density of $1 \times 10^{4}$ cells/100 $\mu \mathrm{L} /$ well. After cultured for $24 \mathrm{~h}$, the viruses Ad5F35-i-lncRNA and Ad5F35-EGFP were added at MOIs of 10 to $200 \mathrm{pfu} / \mathrm{cell}$ in a volume of $100 \mu \mathrm{L} /$ well. Cells were continuously cultured for $48 \mathrm{~h}$ followed by CCK-8 assay analysis. A microplate reader was used to measure the optical density (OD) of each well at $490 \mathrm{~nm}$, the data were used to plot cell viability curves; $* P<0.05$, $* * P<0.01$ and $* * * P<0.001$ compared with the Ad5F35-EGFP-infected group at the same MOI value. B. Cells were infected with Ad5F35-i-lncRNA at an MOI of $100 \mathrm{pfu} / \mathrm{cell}$ and cultured for $24 \mathrm{~h}, 48 \mathrm{~h}$, and $72 \mathrm{~h}$. The cell viability was measured as aforementioned; $* * * P<0.001$ compared with IM-9 cells. 
$100 \mathrm{pfu} / \mathrm{cell}$, Ad5F35-i-lncRNA had no significant effect on the viability of IM-9 cells, which remained more than $90 \%$ at every timepoint. In contrast, the Ad5F35-i-IncRNA-infected cancer cell lines showed gradually decreased viabilities with the prolonging of culture time (Figure $2 \mathrm{~B}$ ).

\section{Effect of i-IncRNA expression on DLBCL cell cycle and apoptosis}

The IM-9 cells infected with Ad5F35-i-lncRNA and Ad5F35-EGFP at an MOI of $100 \mathrm{pfu} /$ cell exhibited no significant changes in the frequencies of cell cycle phases or apoptotic cells. After DLBCL cells were infected with Ad5F35-i-lncRNA, however, higher frequencies of OCILy10 cells were observed in the G0/G1 and G2/M phases, along with a significantly lower frequency of cells in the $\mathrm{S}$ phase; in contrast, SUDHL-4 and DB cells exhibited a slightly lower frequency of cells in the G0/G1 phase, a significantly lower frequency of cells in the $G 2 / \mathrm{M}$ phase, and a higher frequency of cells in the $\mathrm{S}$ phase. After infection with Ad5F35-EGFP, only OCI-Ly10 cells exhibited a higher frequency of cells in the G2/M phase (Figure 3A). After infection with Ad5F35-i-lncRNA, the DLBCL cells exhibited significant increases in apoptotic

A
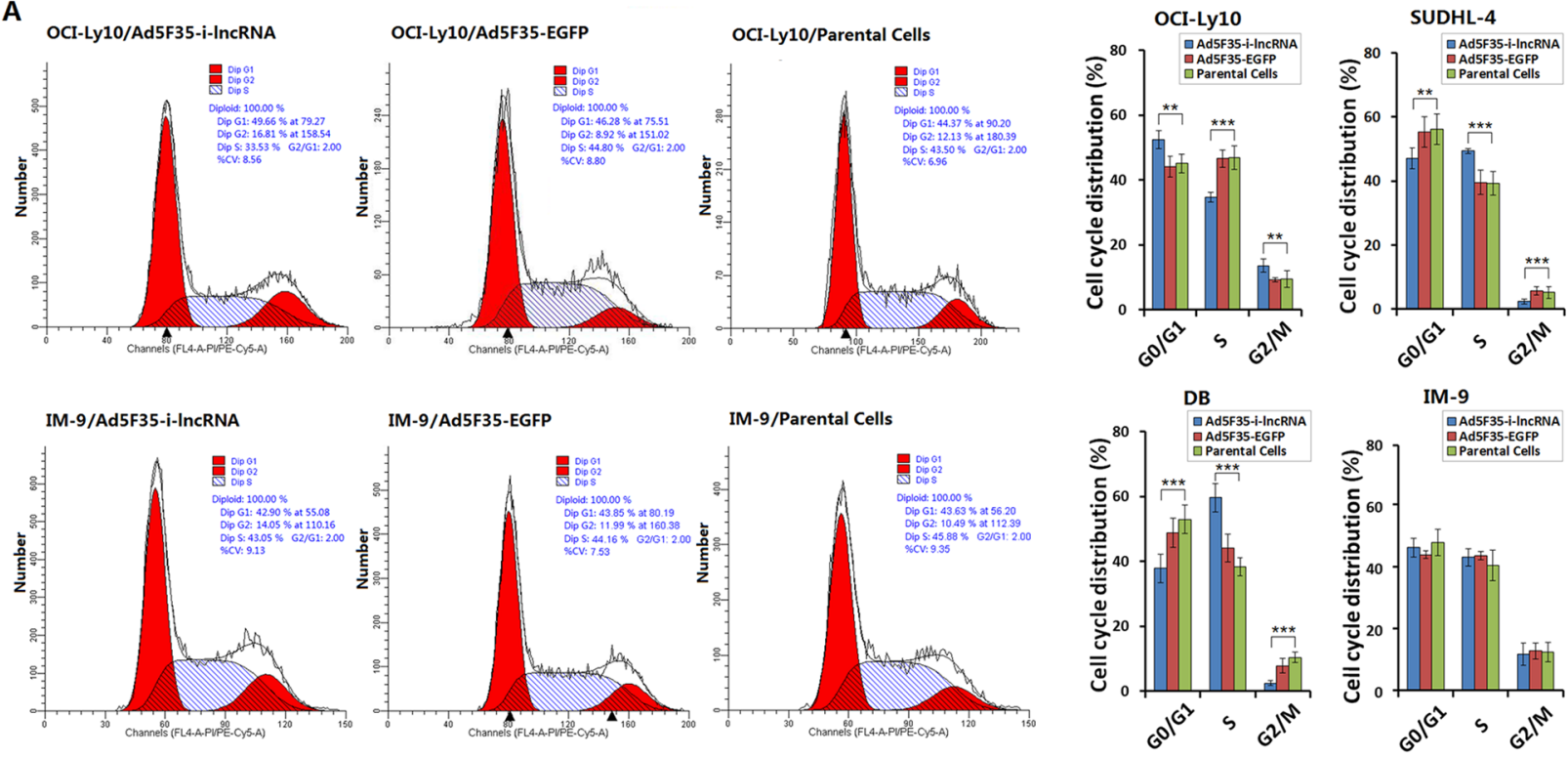

B
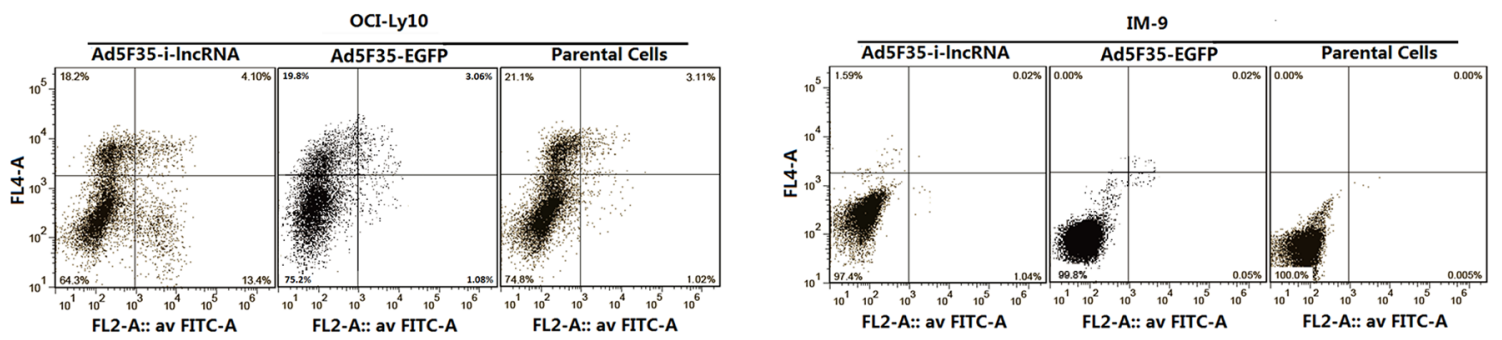

$\mathrm{i}$-IncRNA Induced Apoptosis in DLBCL

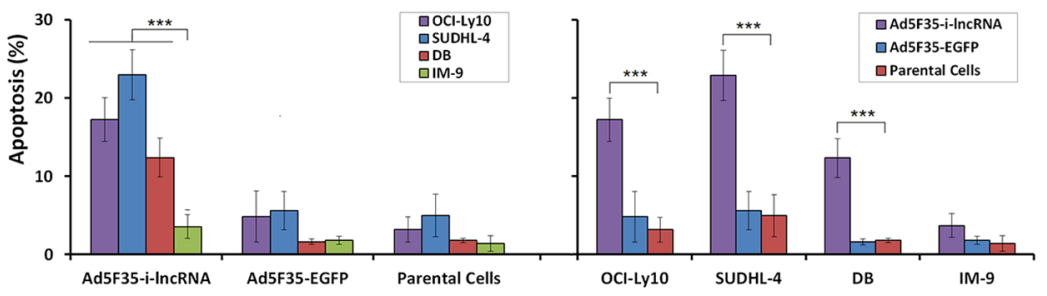

Figure 3: Inhibitory effect of i-IncRNA on cell cycle and apoptosis. A. The four cell lines were cultured in 6-well plates at a density of $1 \times 10^{5}$ cells/100 $\mu \mathrm{L} /$ well for $24 \mathrm{~h}$, then infected with Ad5F35-i-lncRNA or Ad5F35-EGFP at an MOI of $100 \mathrm{pfu} / \mathrm{cell}$. After continuously cultured for $48 \mathrm{~h}$, cells were harvested and fixed in pre-chilled $75 \%$ ethanol, placed in a $4^{\circ} \mathrm{C}$ refrigerator overnight, washed in PBS twice, added the RNase-containing PI staining mixture and incubated in dark for $30 \mathrm{~min}$. Cells were subjected to cell cycle analysis by flow cytometry; $* * P<0.01$ and $* * * P<0.001$. B. Cells were cultured and infected with the viruses as aforementioned, harvested $48 \mathrm{~h}$ later and stained with Annexin V/PI. Cell apoptosis was analyzed by flow cytometric analysis; $* * * P<0.001$. 
frequency, whereas after infection with Ad5F35-EGFP, no change in apoptosis was exhibited in every cell line (Figure 3B).

\section{Effect of i-IncRNA expression on target gene expression in DLBCL cells}

We selected the representative target genes of OncomiRs for an additional Western blot analysis, including the tumor suppressors PTEN, p27kip1, metallopeptidase inhibitor 3 (TIMP3) and reversioninducing-cysteine-rich protein with Kazal motifs (RECK) that are directly targeted by i-lncRNA, and the oncogenic factors p38/mitogen-activated protein kinases (MAPK), Survivin, cyclin-dependent kinase 4 (CDK4) and c-myc that are indirectly related with the changes of cancer cell malignant behaviors mediated by i-lncRNA expression.

When the DLBCL cells were treated with OncomiR inhibitors, the expression levels of some target genes were changed, PTEN was upregulated by the inhibitors for miR-21, miR-125b and miR-155; p27kip 1 was upregulated by the inhibitors for miR-21, miR-155 and miR-221; TIMP3 was upregulated by the inhibitors for miR-21, miR-155, miR-221 and miR-17; RECK was upregulated by all the tested inhibitors (Figure 4A). The results demonstrated that every presentative target gene is regulated by more than one miRNA and every miRNA inhibitor can increase the expression of more than one target gene. After confirmed the interactions between OncomiRs and target genes, the DLBCL cells were infected adenovirus Ad5F35-i-lncRNA, consequently, the expression levels of PTEN, p27 kip1, TIMP3, and RECK were upregulated in DLBCL cells, whereas the expression levels of $\mathrm{p} 38$ / MAPK, survivin, CDK4, and c-myc were downregulated (Figure 4B). In contrast, Ad5F35-i-lncRNA-infected IM-9 cells exhibited slight decreases in the expression of p38/MAPK and survivin but no significant changes in the remaining indicators. Ad5F35-EGFP infection induced no significant change in these proteins in any cell line.

\section{Inhibitory effect of i-IncRNA expression on DLBCL cell xenografts in nude mice}

Ad5F35-i-lncRNA and Ad5F35-EGFP were used to treat SUDHL-4 cell xenografts in nude mice. As soon as day 7 after the initial treatment, the tumor growth speed was significantly lower in the Ad5F35-i-lncRNA treatment group than that in the blank control group, however, the tumor continued to grow. The tumor volumes began to decline by day 28 (Figure 5A). Meanwhile, the tumors in the Ad5F35-EGFP and blank control groups continued to grow; by day 35 , the tumor volumes in the blank control group exceeded the upper limit of $1,500 \mathrm{~mm}^{3}$ permitted by the Ethics Committee of Animal Studies, and thus, the experiment was terminated.
The tumor specimens were removed and weighed; tumors from the Ad5F35-i-lncRNA group weight significantly less than those from the Ad5F35-EGFP and blank control groups (Figure 5B). The tumor specimens were subjected to immunohistochemical staining to analyze the expression of miRNA target gene products, and the results revealed significant increases in the expression levels of PTEN and p27 $7^{\text {kip } 1}$ in the Ad5F35-i-lncRNA group and significant decreases in the expression levels of p38/MAPK and survivin. TUNEL labeling indicated a significantly higher apoptosis rate in the Ad5F35-ilncRNA group (Figure 5C). Although the expressed i-lncRNA competed with the target gene mRNAs to bind to OncomiRs and did not direct change OncomiRs expression, we still detected miRNA expressed in DLBCL xenograft tumors. The i-lncRNA-involved OncomiRs were not always decreased, miR-21 was decreased, miR-221 was increased, and the expression of miR-155, miR-17, miR-19a and miR-20a was not changed, compared with the control group. Interestingly, we also found miR-150 was decreased and miR-34a was increased, suggesting that the expression changes in DLBCL cells after i-lncRNA expression are more complicated (Figure 5D).

\section{DISCUSSION}

DLBCL is the most common type of NHL. Studies have shown that many miRNAs regulate the expression and function of target genes and are thus involved in the development and progression of DLBCL. OncomiRs are a type of miRNA that, upon overexpression, can inactivate certain target genes with tumor suppressor activity and promote the proliferation and metastasis of cancer cells, including DLBCL cells. Studies of clinical DLBCL specimens have shown that upregulated miR-21 expression inhibits the expression of forkhead box protein O1 (FOXO1) and PTEN, thereby increasing the activity of the phosphatidylinositol 3-kinase (PI3K)/protein kinase B (AKT)/mammalian target of rapamycin (mTOR) signaling pathway and imparting more malignant biological characteristics to DLBCL cells. miR-21 overexpression significantly shortens the PFS and OS of DLBCL patients [22]. Many types of malignant tumors, including DLBCL, exhibit high levels of miR-155 expression. In addition, in vivo miR-155 transfection has shown to induce lymphoma in murine B cells [23]. miR-155 inactivates the tumor suppressor gene phosphatidylinositol-3,4,5-trisphosphate 5 -phosphatase 1 (SHIP1), thereby promoting the tumor necrosis factor (TNF)- $\alpha$-dependent growth of DLBCL cells $[23,24]$. In animal models of DLBCL, miR155 has been shown to block the transforming growth factor (TGF)- $\beta 1$-induced activation of retinoblastoma protein $(\mathrm{RB})$, thereby promoting dissociation of the phosphorylated RB (pRB)-E2F1 complex and enabling E2F1 to promote gene transcription and cell cycle progression [25]. High levels of miR-155 also inactivate 
human germinal center-associated lymphoma (HGAL) and mothers against decapentaplegic homolog 5 (SMAD5) $[26,27]$, thus increasing the invasiveness of DLBCL cells and leading to a poor clinical prognosis. Strong miR-125a/miR-125b expression directly inhibits the activity of tumor necrosis factor alpha-induced protein 3 (TNFAIP3), thereby activating the NF- $\kappa \mathrm{B}$ signaling pathway and promoting the progression of DLBCL [28]. Overexpression of miR-17 92 cluster (miR-17, miR-18a, miR-19a, miR-20a, miR-19b-1, and miR-92-1) induces
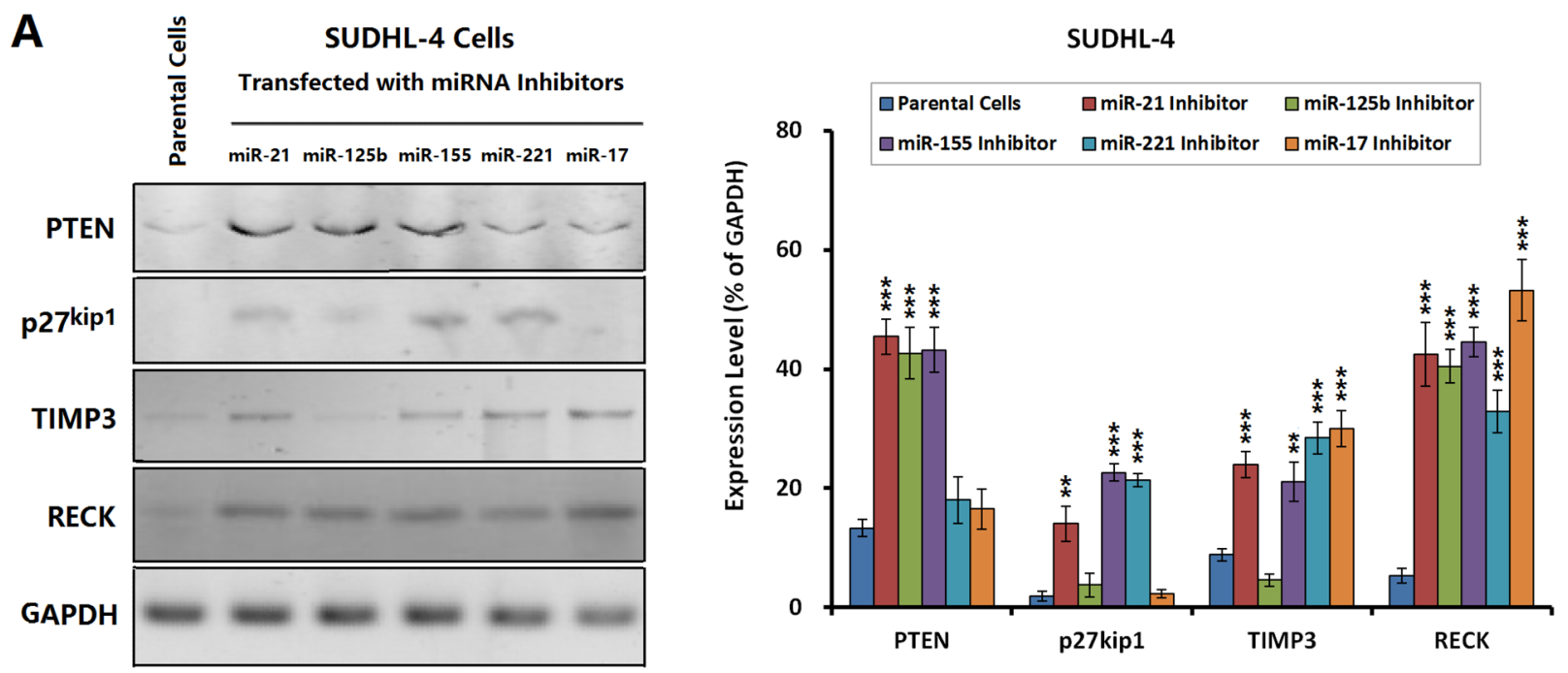

B
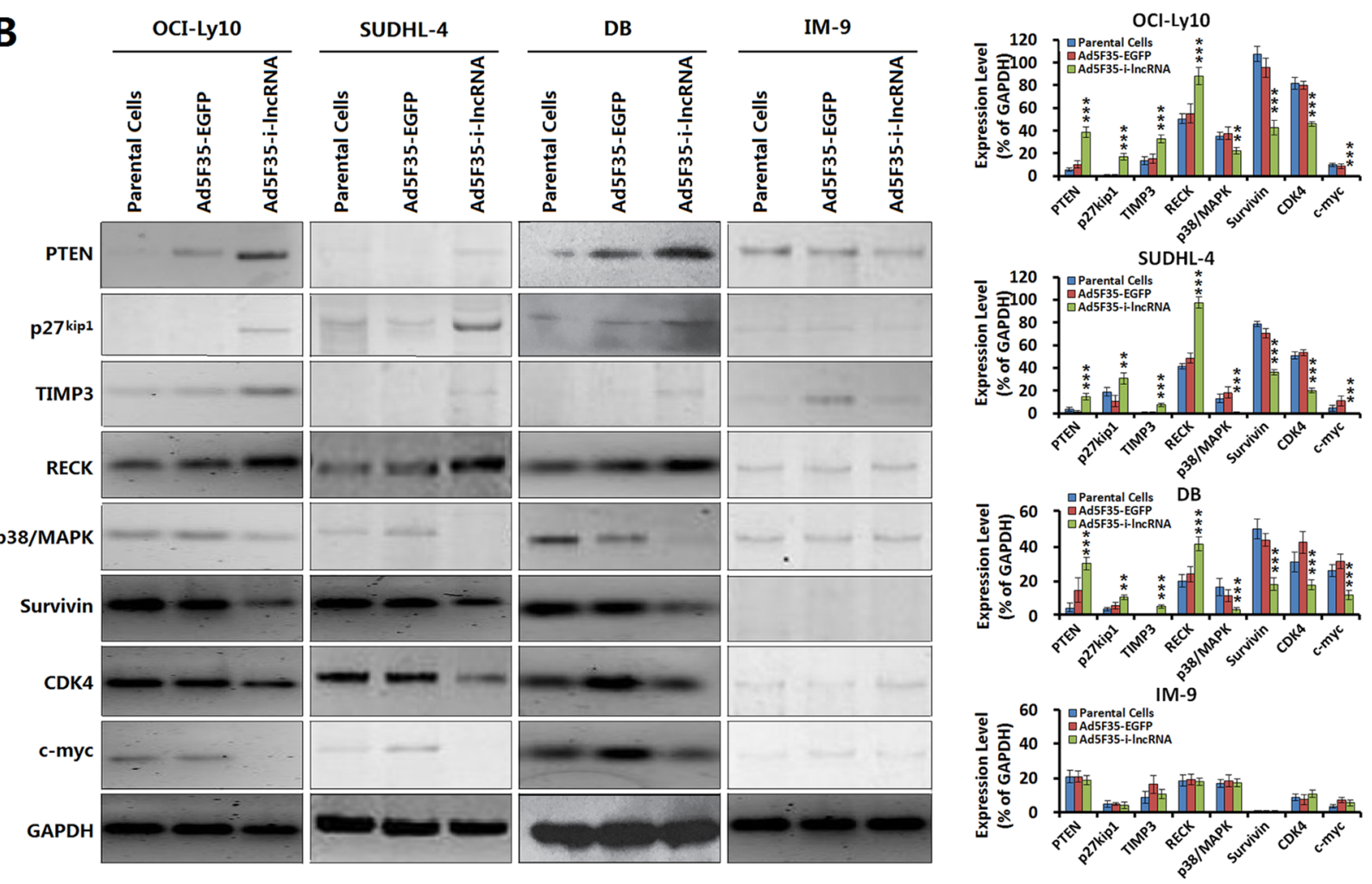

Figure 4: Changes of OncomiR target gene expression mediated by i-IncRNA. A. SUDHL-4 cells were seeded into 24-well plates at a density of $1 \times 10^{6}$ cells $/ 100 \mu \mathrm{L} /$ well and incubated with the indicated miRNA inhibitors at a concentration of $100 \mathrm{nmol} / \mathrm{L}$ for $48 \mathrm{~h}$, the harvested cells were managed to detect the expressions of OncomiR target genes. GAPDH was used as the loading control. The densitometry analysis of every protein was performed, normalized with GAPDH content; $* * P<0.01$ and $* * * P<0.001$ compared with the corresponding parental cells. B. The four cell lines were planted in 24-well plates at a density of $1 \times 10^{6}$ cells/100 $\mu \mathrm{L} /$ well for $24 \mathrm{~h}$, then infected with Ad5F35-i-lncRNA or Ad5F35-EGFP at an MOI of $100 \mathrm{pfu} / \mathrm{cell}$. After continuously cultured for $48 \mathrm{~h}$, cells were harvested for isolation of total proteins, and the expressions of the indicated proteins were examined by Western blot. The densitometry analysis of every protein was performed, normalized with GAPDH content; $* * P<0.01$ and $* * * P<0.001$ compared with the corresponding parental cells. 

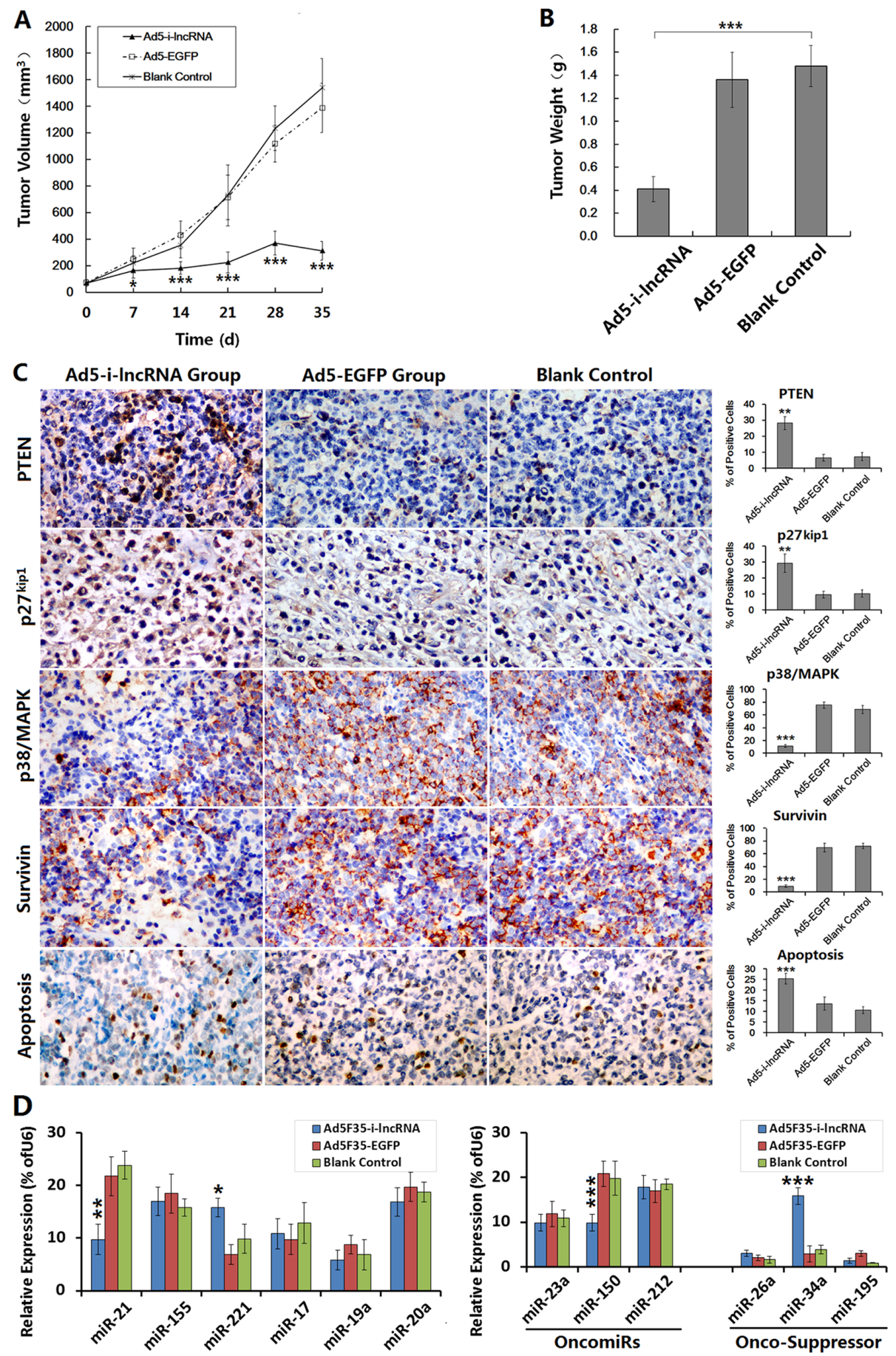

Figure 5: Antitumor efficacy of i-IncRNA on DLBCL xenografts in mouse model. A. SUDHL-4 cells were used to establish the xenograft tumor models. After tumors had developed, the mice were randomly assigned into three groups (Ad5F35-i-lncRNA group, Ad5F35-EGFP group, blank control group), 10 mice in every group. The virus treatment groups were received 5 injections of total viral dose of $1 \times 10^{9} \mathrm{pfu} / 100 \mu \mathrm{L} /$ mouse, one injection every other day. The blank control group was synchronously received injections of saline with same volume. After treatments, the tumor size was measured weekly and the tumor volume was calculated as "the maximum diameter $\times$ minimum diameter ${ }^{2} \times 0.5$ " and used to plot growth curves; $* P<0.05$ and $* * * P<0.001$ compared with the blank control group. B. The experimental observation was terminated at day 35 after the first treatment. The tumor specimens were harvested and weighed; $* * * P<0.001$. C. The formalin-fixed, paraffin-embedded tumor sections were prepared for immunohistochemical staining to observe the expression of miRNA target gene expression, and the TUNEL assay was performed to evaluate cell apoptosis. For each slice, the positive cells were counted within 5 medium-power magnification fields of view (20× objective lens) under a microscope; original magnification: $200 \times$; $* * P<0.01$ and $* * * P<0.001$ compared with the blank control group. D. The fresh tumor tissues were prepared to detect miRNA expression by qRT-PCR; ${ }^{*} P<0.05, * * P<0.01$ and $* * * P<0.001$ compared with the blank control group. 
lymphoma [29]. In addition, malignant B cell proliferation in miR-17 92-overexpressing mice is associated with PTEN and BCL-2-related ovarian death gene (BIM) inhibition [30, 31], as well as $\mathrm{PH}$ domain and leucine rich repeat protein phosphatase 2 (PHLPP2) suppression and PI3K/AKT signaling pathway activation $[32,33]$. In contrast to OncomiRs, DLBCL cells might also exhibit decreases in or losses of expression of certain miRNAs for which the target genes are oncogenic; accordingly, the decreased expression of these tumor suppressor miRNAs is associated with increased oncogene activity and consequent cancer proliferation, invasion, and metastasis.

In DLBCL cells, changes in miRNA expression levels affect the expression and functions of many target genes and the activity of many signaling pathways, and are thus involved in the development and progression of DLBCL. Accordingly, miRNAs have become promising molecular targets for the treatment of DLBCL. Generally, two miRNA-targeting treatment regimens are available: the use of a miRNA antagonist or inhibitor to suppress OncomiR expression or activity and a targeted increase in the expression of tumor suppressor miRNA [34, 35]. A previous study demonstrated that the in vivo administration of a polylysine-conjugated peptide and nucleic acid nanoparticle-coated antisense nucleic acid of miR-155 induced apoptosis and significantly reduced tumor growth in a murine pre-B-cell lymphoma model [36]. Systemic miR-34a administration downregulated FOXP1 expression and induced apoptosis in a DLBCL xenograft mouse model, leading to significant tumor suppressing effect [37]. However, these regimens only target single miRNAs, and thus, their effects are transient and limited. DLBCL is associated with the abnormal expression of multiple genes, as well as different clinical characteristics, treatment responses, and prognoses; this disease involves extensive and complex miRNA regulation processes, allowing cancer cells to easily regain proliferative activity through alternate bypass pathways. Therefore, an intervention strategy simultaneously targeting multiple miRNAs would yield more extensive inhibitory effects and finally provide better outcomes for DLBCL treatment.

Based on our literature review, we selected several OncomiRs proven to be expressed very strongly in DLBCL and generated a tandem sequence containing 10 copies of the complementary binding sequences of these miRNAs; we then used this tandem sequence to design an i-lncRNA and ensured a high copy expression of this molecule in DLBCL cells through adenoviral vector infection and mediation. The i-lncRNA molecules outcompeted OncomiRs for binding to target gene mRNAs, thereby consuming large amounts of OncomiRs; this protected the target genes of OncomiRs and enabled many tumor suppressor factors to play an effective anticancer role. The in vitro cytology experiments confirmed that the i-lncRNA expression significantly inhibited cell proliferation and induced apoptosis in DLBCL cell lines OCI-Ly10, SUDHL-4, and DB but failed to induce significant effects in normal $\mathrm{B}$ lymphocytes. The i-lncRNA expression had different effects on cell cycle phases in different DLBCL cell lines, in OCI-Ly10 cells, the frequencies of cells in the G0/G1 and $\mathrm{G} 2 / \mathrm{M}$ phases were increased, whereas the frequency in the $\mathrm{S}$ phase was significantly decreased; in contrast, in SUDHL-4 and DB cells, the frequencies of cells were slightly decreased in the G0/G1 phase, increased in the $\mathrm{S}$ phase, and significantly decreased in the G2/M phase. An analysis of the OncomiR target gene product expression found significant changes in the protein expression of DLBCL cells with acquired i-lncRNA expression; notably, the expression levels of tumor suppressor genes (PTEN, p2 $7^{\text {kip1 }}$, TIMP3, RECK) were upregulated, whereas those of oncogenes (p38/MAPK, survivin, CDK4, c-myc) were downregulated, suggesting that high-copy i-lncRNA expression protected the target genes of OncomiRs. Furthermore, we established SUDHL-4 cell xenografts in nude mice and confirmed the effectiveness of our anticancer strategy in which i-lncRNA was used to competitively consume OncomiRs, thus demonstrating that this treatment strategy involving adenovirus-mediated i-lncRNA expression significantly inhibited the growth of DLBCL xenografts.

Up till now, there is no report about simultaneous intervention of multiple OncomiRs to treat cancer. We have developed a new anticancer intervention strategy that simultaneously targets a group of OncomiRs in DLBCL and have demonstrated that this strategy eliminates the limitations of single miRNA-targeting treatments, thereby significantly improving and prolonging the anticancer effects while exhibiting an excellent safety profile. Our strategy was simultaneously based on multiple highly expressed OncomiRs in DLBCL and could be used as an effective and reliable technology for DLBCL therapy. This group of chose OncomiRs may not be the optimal combination, and further study is necessary to optimize the most effective composition of OncomiRs for DLBCL and other cancers.

\section{MATERIALS AND METHODS}

\section{Construction of the experimental vectors}

A tandem sequence containing 10 copies of complementary sequences to the seed sequences of highly expressed OncomiRs (miR-21, miR-155, miR221/222, miR-125a-5p/125b, miR-146a/146b-5p, miR17, miR-19a/19b, miR-20a/20b) in DLBCL (Table 1) was generated and used as the encoding sequence for i-lncRNA. A CACC-box and EcoRI site were introduced at the 5'-end, a SalI site was introduced at the 3'-end, and a stop codon (TAA) was introduced into upstream and downstream of the i-lncRNA sequence. The sequence was inserted into the EcoRI + SalI sites of plasmid pDC315 
Table 1: OncomiRs and their complementary binding sequence within i-lncRNA

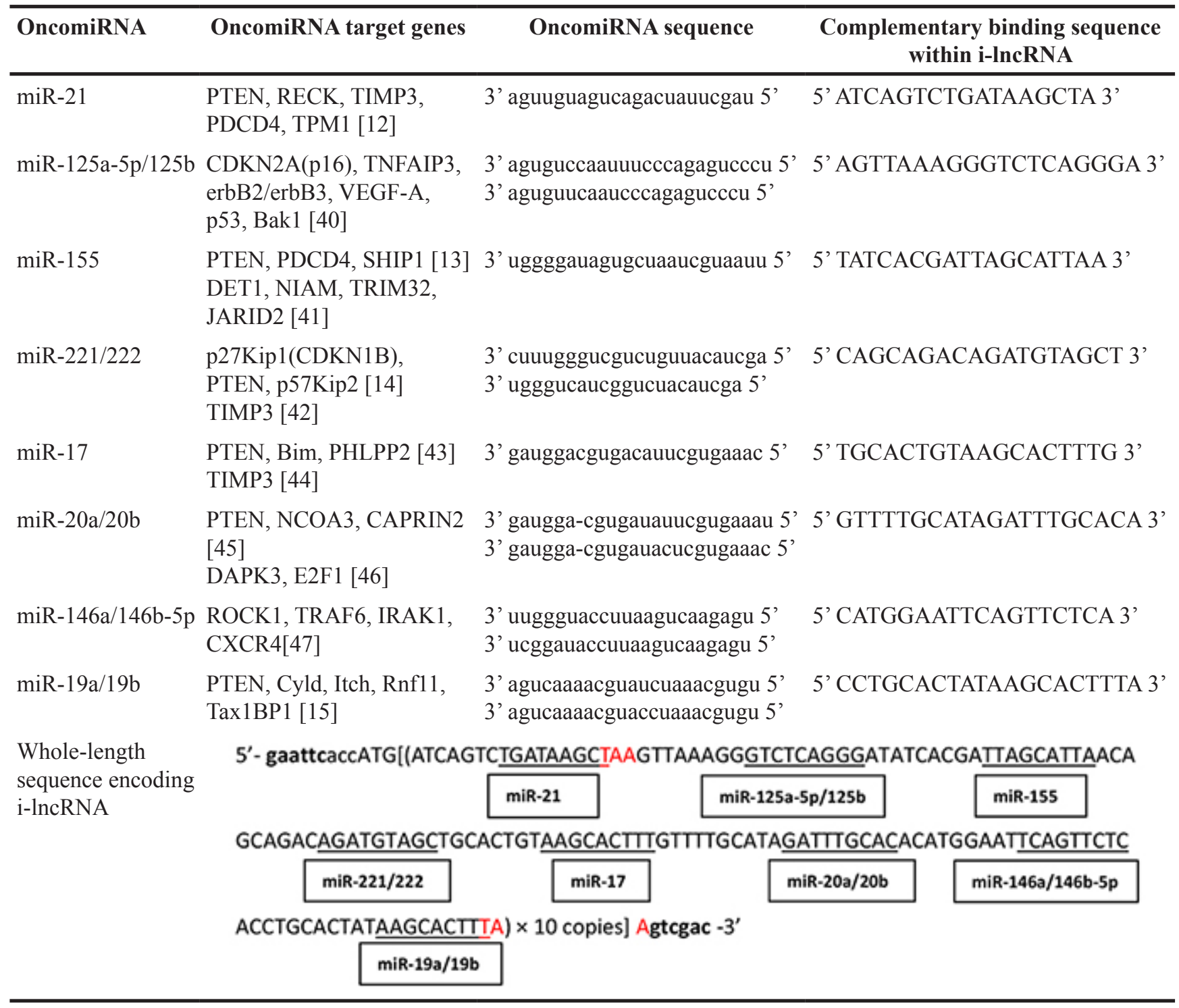

(Microbix Biosystems Inc., Mississauga, Ontario, Canada) to construct the i-lncRNA-expressing plasmid pDC315-i-lncRNA. This plasmid and the adenovirus packaging plasmid pAd5F35 were co-transfected into HEK293 cells to recombine the adenovirus Ad5F35i-lncRNA. Ad5F35-EGFP armed with the enhanced green fluorescent protein (EGFP) gene was used as a negative control adenovirus [38, 39]. The adenoviruses were amplified in large quantities in HEK293 cells and purified via cesium chloride gradient centrifugation. The virus titer was determined through a TCID50 assay. The binding sequence for miR-21 and miR-155 were inserted into the 3'-untranslated region (UTR) of the luciferase vector pGL3-Control (Promega Corporation, Madison, WI, USA) to generate the plasmid pGL3-miRs for the luciferase assay.

\section{Cell line culture and virus infection}

DLBCL cell lines (OCI-Ly10, SUDHL-4, DB) were kindly provided by Professor Junmin Li (Department of Hematology, Affiliated Ruijin Hospital of Shanghai JiaoTong University, Shanghai, China). A normal human peripheral B cell line (IM-9) was obtained from the Cell Bank of the Institute of Biochemistry \& Cell Biology, Chinese Academy of Sciences (Shanghai, China), and cultured following the supplier's instructions. The cell lines were infected with the experimental adenovirus Ad5F35-i-lncRNA or the control adenovirus Ad5F35EGFP at multiplicities of infection (MOIs) of 10 to 200 plaque-forming units (pfu)/cell to establish virus-infected cell sublines. The luciferase assay was performed in the five cell lines after transfected with OncomiR inhibitors 
(GenePharma Inc., Shanghai, China) according to the manufacturer's protocol. The vector pGL3-Control was the positive control, and the relative luciferase activity of pGL3-miRs was normalized with the data of pGL3-Control.

\section{Detection of gene expression}

Cell lines including the parental cell lines and cell sublines infected with viruses were cultured for 48 $\mathrm{h}$ and harvested. A part of cells were seeded into 24well plates at a density of $1 \times 10^{6}$ cells $/ 100 \mu \mathrm{L} /$ well . After dilution in serum-free medium, a part of cells was incubated with miRNA inhibitors at a concentration of $100 \mathrm{nmol} / \mathrm{L}$ for $48 \mathrm{~h}$ and harvested for detecting the expressions of OncomiR target genes. Another part of cells was infected with Ad5F35-i-lncRNA and Ad5F35EGFP at an MOI of $100 \mathrm{pfu} /$ cell in a volume of 100 $\mu \mathrm{L}$, and the cells were harvested $48 \mathrm{~h}$ later. Total RNA was extract for detection of i-lncRNA and miRNA expression by real-time quantitative reverse transcriptionpolymerase chain reaction (qRT-PCR). The specific PCR primers used for i-lncRNA detection were lncR-F (5'-CACCATGATCAGTCTGATAAG-3') and lncR-R (5'-TCAGCCCTGAGACCCTAACTC-3'). Total protein was extracted for detection of protein expression by Western blot. Antibodies used for Western blot were purchased from Santa Cruz Biotechnology, Inc. (Santa Cruz, CA, USA), except the mouse anti-Survivin antibody was purchased from Abcam Inc. (Cambridge, MA, USA).

\section{Detection of cell proliferation}

A cholecystokinin-8 (CCK-8) assay was performed to analyze the effect of Ad5F35-i-lncRNA infection on DLBCL cell proliferation; Ad5F35-EGFP was used as a negative viral control, and IM-9 was used as a normal cell control. Cells were harvested in the exponential growth phase, diluted with $10 \%$ serum-containing medium, and seeded into 96-well plates at a density of $1 \times 10^{4}$ cells $/ 100 \mu \mathrm{L} /$ well. After cultured for $24 \mathrm{~h}$, the viruses was diluted with serum-free medium and added to the wells at MOIs of 10 to $200 \mathrm{pfu} / \mathrm{cell}$ in a volume of $100 \mu \mathrm{L} /$ well. Eight replicates were generated for each MOI. The cells were cultured in an incubator for 2 h. Next, the medium was replaced with serum-containing medium (100 $\mu \mathrm{L} /$ well), and the cells were cultured for 48 $\mathrm{h}$ followed by CCK-8 assay analysis according to the kit instructions. A microplate reader was used to measure the optical density (OD) of each well at $490 \mathrm{~nm}$, the data were used to plot cell viability curves. The experiments were repeated at an MOI of $100 \mathrm{pfu} /$ cell and at cell culture time for $24 \mathrm{~h}, 48 \mathrm{~h}$, and $72 \mathrm{~h}$.

\section{Flow cytometric analysis of cell cycle and apoptosis}

Cells were infected with Ad5F35-i-lncRNA or Ad5F35-EGFP at a MOI of $100 \mathrm{pfu} / \mathrm{cell}$ and harvested
$48 \mathrm{~h}$ later. A part of cells were centrifuged at 1,000 rpm for 5 min to wipe off cell debris, and fixed in pre-chilled $75 \%$ ethanol and placed in a $4^{\circ} \mathrm{C}$ refrigerator overnight. After two times of wash in phosphate buffered saline (PBS), the RNase-containing propidium iodide (PI) staining mixture was added into the cell suspension, following incubation in dark for $30 \mathrm{~min}$, the cells were subjected to cell cycle analysis by flow cytometry. Another part of cells were stained with Annexin V/PI (Alpha Diagnositic International, San Antonio, TX) and subjected to flow cytometric apoptosis analysis.

\section{Anti-DLBCL xenograft in mouse model}

Forty healthy inbred BALB/C nude mice (20 males and 20 females), 5-week-old, were provided by the Shanghai SLAC Laboratory Animal Center, Chinese Academy of Sciences (Shanghai, China). SUDHL-4 cells were harvested in the exponential growth phase, suspended, and subcutaneously injected into the right armpits of mice at a dose of $1 \times 10^{7}$ cells $/ 100 \mu \mathrm{L} /$ mouse. Twenty-one days later, tumors had developed in 34 mice (85\%) with approximate diameters of $0.5-0.8 \mathrm{~cm}$. The four mice with the two largest and smallest tumors were excluded, and the remaining 30 mice were randomly assigned into three groups (Ad5F35-ilncRNA group, Ad5F35-EGFP group, blank control group) for a total of 10 mice per group. For the virus treatment groups, the respective adenovirus virus was injected into the tumors at multiple sites with a dosage schedule of five doses at $2 \times 10^{8} \mathrm{pfu} / 100 \mu \mathrm{L} /$ mouse every 2 days. For the blank control group, saline was injected according to the same dosing schedule (100 $\mu \mathrm{L} /$ mouse $/$ dose $)$. After treatment, the tumor size was measured weekly; the tumor volume was calculated as "the maximum diameter $\times$ minimum diameter ${ }^{2}$ $\times 0.5$ " and used to plot growth curves.

The experimental observation was terminated if the mean tumor volume in any group exceeded the upper limit of $1,500 \mathrm{~mm}^{3}$ permitted by the Ethics Committee of Animal Studies. At termination, 3\% sodium pentobarbital was intraperitoneally injected to anesthetize and kill the mice, and tumor specimens were harvested and weighed. A part of fresh tumor tissues was prepared to detect miRNA expression by qRT-PCR. Another part of tumors was fixed in $10 \%$ neutral buffered formalin, embedded in paraffin, and sectioned for immunohistochemical staining to observe the expression of miRNA target gene expression (e.g., PTEN [phosphatase and tensin homolog deleted in chromosome 10], p2 $7^{\text {kip1 }}, \mathrm{p} 38 /$ MAPK, survivin). Terminal deoxynucleotidyl transferase dUTP nick-end labeling (TUNEL) was performed to evaluate apoptosis. For each slice, the number of positive cells was counted within 5 medium-power magnification fields of view (20× objective lens) under a microscope.

\section{Statistical analysis}

The experimental data were statistically analyzed by one-way analysis of variance (ANOVA) and SNK-q test. The 
software package PASW Statistics 18 was used. The $P$ values less than 0.05 were considered statistically significant.

\section{ACKNOWLEDGMENTS}

This work was supported by the projects of National Natural Science Foundation of China (81570179 and 81170499 to J. C., 81402565 to W. J.), and 973 Program of National Ministry of Science and Technology of China (2011CB965100 to J.W.).

\section{CONFLICTS OF INTEREST}

The authors have any conflict of interest to disclose.

\section{REFERENCES}

1. Lenz G. Novel therapeutic targets in diffuse large B-cell lymphoma. EJC Suppl. 2013;11:262-263.

2. Witkowska M, Smolewski P. Emerging immunotherapy and strategies directly targeting $\mathrm{B}$ cells for the treatment of diffuse large B-cell lymphoma. Immunotherapy. 2015;7:37-46.

3. Shin HJ, Yoon DH, Lee HS, Oh SY, Yang DH, Kang HJ, Chong SY, Park Y, Do Y, Lim SN, Jo JC, Lee WS, Chung J. Consortium for Improving Survival of Lymphoma. Induction chemotherapy followed by up-front autologous stem cell transplantation may have a survival benefit in high-risk diffuse large B cell lymphoma patients. Exp Hematol. 2015; doi: 10.1016/j.exphem.2015.08.008.

4. Chan B, Manley J, Lee J, Singh SR. The emerging roles of microRNAs in cancer metabolism. Cancer Lett. 2015;356:301-308

5. Phuah NH, Nagoor NH. Regulation of microRNAs by natural agents: new strategies in cancer therapies. Biomed Res Int. 2014;2014:804510.

6. Calin GA, Dumitru CD, Shimizu M, Bichi R, Zupo S, Noch E, Aldler H, Rattan S, Keating M, Rai K, Rassenti L, Kipps T, Negrini M, Bullrich F,Croce CM. Frequent deletions and down-regulation of micro- RNA genes miR15 and miR16 at 13q14 in chronic lymphocytic leukemia. Proc Natl Acad Sci U S A. 2002;99:15524-15529.

7. Hata A, Lieberman J. Dysregulation of microRNA biogenesis and gene silencing in cancer. Sci Signal. 2015;8:re3.

8. Su Y, Li X, Ji W, Sun B, Xu C, Li Z, Qian G, Su C. Small molecule with big role: MicroRNAs in cancer metastatic microenvironments. Cancer Lett. 2014;344:147-156.

9. Lim EL, Trinh DL, Scott DW, Chu A, Krzywinski M, Zhao Y, Robertson AG, Mungall AJ, Schein J, Boyle M, Mottok A, Ennishi D, Johnson NA,Steidl C, Connors JM, Morin RD, Gascoyne RD, Marra MA. Comprehensive miRNA sequence analysis reveals survival differences in diffuse large B-cell lymphoma patients. Genome Biol. 2015;16:18.

10. Wang K, Xu Z, Wang N, Xu T, Zhu M. MicroRNA and gene networks in human diffuse large B-cell lymphoma. Oncol Lett. 2014;8:2225-2232.
11. Handal B, Enlow R, Lara D, Bailey M, Vega F, Hu P, Lennon A. Investigating the expression of oncogenic and tumor suppressive microRNA in DLBCL. J Assoc Genet Technol. 2013;39:14-20.

12. Petrović N. miR-21 Might be Involved in Breast Cancer Promotion and Invasion Rather than in Initial Events of Breast Cancer Development. Mol Diagn Ther. 2016 Feb 18. doi: 10.1007/s40291-016-0186-3.

13. Yamanaka $Y$, Tagawa $H$, Takahashi N, Watanabe A, Guo YM, Iwamoto K, Yamashita J, Saitoh H, Kameoka Y, Shimizu N,Ichinohasama R, Sawada K. Aberrant overexpression of microRNAs activate AKT signaling via down-regulation of tumor suppressors in natural killer-cell lymphoma/leukemia. Blood. 2009;114:3265-3275.

14. Di Martino MT, Gullà A, Cantafio ME, Lionetti M, Leone E, Amodio N, Guzzi PH, Foresta U, Conforti F, Cannataro M, Neri A,Giordano A, Tagliaferri P, Tassone P. In vitro and in vivo anti-tumor activity of miR-221/222 inhibitors in multiple myeloma. Oncotarget. 2013;4:242-255. doi: 10.18632 /oncotarget. 820 .

15. Battistella M, Romero M, Castro-Vega LJ, Gapihan G, Bouhidel F, Bagot M, Feugeas JP, Janin A. The High Expression of the microRNA 17-92 Cluster and its Paralogs, and the Downregulation of the Target Gene PTEN, Is Associated with Primary Cutaneous B-Cell Lymphoma Progression. J Invest Dermatol. 2015;135:1659-1667.

16. Gu L, Song G, Chen L, Nie Z, He B, Pan Y, Xu Y, Li R, Gao T, Cho WC, Wang S. Inhibition of miR-21 induces biological and behavioral alterations in diffuse large B-cell lymphoma. Acta Haematol. 2013;130:87-94.

17. Tessitore A, Cicciarelli G, Mastroiaco V, Del Vecchio F, Capece D, Verzella D, Fischietti M, Vecchiotti D, Zazzeroni F, Alesse E. Therapeutic use of microRNAs in cancer. Anticancer Agents Med Chem. 2015;16:7-19.

18. Stahlhut C, Slack FJ. Combinatorial Action of MicroRNAs let-7 and miR-34 effectively synergizes with erlotinib to suppress non-small cell lung cancer cell proliferation. Cell Cycle. 2015;14:2171-2180.

19. Cheng CJ, Bahal R, Babar IA, Pincus Z, Barrera F, Liu C, Svoronos A, Braddock DT, Glazer PM, Engelman DM, Saltzman WM, Slack FJ. MicroRNA silencing for cancer therapy targeted to the tumour microenvironment. Nature. 2015;518:107-110.

20. Cheng CJ, Slack FJ. The duality of oncomiR addiction in the maintenance and treatment of cancer. Cancer J. 2012;18:232-237.

21. Maltby S, Plank M, Ptaschinski C, Mattes J, Foster PS. MicroRNA function in mast cell biology: protocols to characterize and modulate microRNA expression. Methods Mol Biol. 2015;1220:287-304.

22. Go H, Jang JY, Kim PJ, Kim YG, Nam SJ, Paik JH, Kim TM, Heo DS, Kim CW, Jeon YK. MicroRNA-21 plays an oncogenic role by targeting FOXO1 and activating the PI3K/ AKT pathway in diffuse large B-cell lymphoma. Oncotarget. 2015;6:15035-15049. doi: 10.18632/oncotarget.3729. 
23. Mashima R. Physiological roles of miR-155. Immunology. 2015;145:323-333.

24. Pedersen IM, Otero D, Kao E, Miletic AV, Hother C, Ralfkiaer E, Rickert RC, Gronbaek K, David M. Onco-miR-155 targets SHIP1 to promote TNFalpha-dependent growth of B cell lymphomas. EMBO Mol Med. 2009;1:288-295.

25. Jiang D, Aguiar RC. MicroRNA-155 controls RB phosphorylation in normal and malignant $\mathrm{B}$ lymphocytes via the noncanonical TGF- $\beta 1 /$ SMAD5 signaling module. Blood. 2014;123:86-93.

26. Dagan LN, Jiang X, Bhatt S, Cubedo E, Rajewsky K, Lossos IS. miR-155 regulates HGAL expression and increases lymphoma cell motility. Blood. 2012;119:513-520.

27. Rai D, Kim SW, McKeller MR, Dahia PL, Aguiar RC. Targeting of SMAD5 links microRNA-155 to the TGF-beta pathway and lymphomagenesis. Proc Natl Acad Sci U S A. 2010;107:3111-3116.

28. Kim SW, Ramasamy K, Bouamar H, Lin AP, Jiang D, Aguiar RC. MicroRNAs miR-125a and miR-125b constitutively activate the NF- $\kappa$ B pathway by targeting the tumor necrosis factor alpha-induced protein 3 (TNFAIP3, A20). Proc Natl Acad Sci U S A. 2012;109:7865-7870.

29. Sandhu SK, Fassan M, Volinia S, Lovat F, Balatti V, Pekarsky Y, Croce CM. B-cell malignancies in microRNA

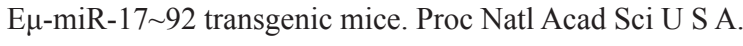
2013;110:18208-18213.

30. Ventura A, Young AG, Winslow MM, Lintault L, Meissner A, Erkeland SJ, Newman J, Bronson RT, Crowley D, Stone JR, Jaenisch R, Sharp PA,Jacks T. Targeted deletion reveals essential and overlapping functions of the miR-17 through 92 family of miRNA clusters. Cell. 2008;132:875-886.

31. Xiao C, Srinivasan L, Calado DP, Patterson HC, Zhang B, Wang J, Henderson JM, Kutok JL, Rajewsky K. Lymphoproliferative disease and autoimmunity in mice with increased miR-17-92 expression in lymphocytes. Nat Immunol. 2008;9:405-414.

32. Rao E, Jiang C, Ji M, Huang X, Iqbal J, Lenz G, Wright G, Staudt LM, Zhao Y, McKeithan TW, Chan WC, Fu K. The miRNA-17 92 cluster mediates chemoresistance and enhances tumor growth in mantle cell lymphoma via PI3K/ AKT pathway activation. Leukemia. 2012;26:1064-1072.

33. Musilova K, Mraz M. MicroRNAs in B-cell lymphomas: how a complex biology gets more complex. Leukemia. 2015;29:1004-1017.

34. Troppan K, Wenzl K, Deutsch A, Ling H, Neumeister P, Pichler M. MicroRNAs in diffuse large B-cell lymphoma: implications for pathogenesis, diagnosis, prognosis and therapy. Anticancer Res. 2014;34:557-564.

35. Garzon R, Marcucci G, Croce CM. Targeting microRNAs in cancer: rationale, strategies and challenges. Nat Rev Drug Discov. 2010;9:775-789.

36. Babar IA, Cheng CJ, Booth CJ, Liang X, Weidhaas JB, Saltzman WM, Slack FJ. Nanoparticle-based therapy in an in vivo microRNA-155 (miR-155)-dependent mouse model of lymphoma. Proc Natl Acad Sci U S A. 2012;109:E1695-1704.

37. Craig VJ, Tzankov A, Flori M, Schmid CA, Bader AG, Müller A. Systemic microRNA-34a delivery induces apoptosis and abrogates growth of diffuse large B-cell lymphoma in vivo. Leukemia. 2012;26:2421-2424.

38. Hu H, Qiu Y, Guo M, Huang Y, Fang L, Peng Z, Ji W, Xu Y, Shen S, Yan Y, Huang X, Zheng J, Su C. Targeted Hsp70 expression combined with CIK-activated immune reconstruction synergistically exerts antitumor efficacy in patient-derived hepatocellular carcinoma xenograft mouse models. Oncotarget. 2015;6:1079-1089. doi: 10.18632/oncotarget.2835.

39. Zhang Y, Fang L, Zhang Q, Zheng Q, Tong J, Fu X, Jiang $\mathrm{X}, \mathrm{Su} \mathrm{C}, \mathrm{Zheng} \mathrm{J}$. An oncolytic adenovirus regulated by a radiation-inducible promoter selectively mediates hSulf-1 gene expression and mutually reinforces antitumor activity of I131-metuximab in hepatocellular carcinoma. Mol Oncol. 2013;7:346-358.

40. Yin H, Sun Y, Wang X, Park J, Zhang Y, Li M, Yin J, Liu Q, Wei M. Progress on the relationship between miR-125 family and tumorigenesis. Exp Cell Res. 2015;339:252-260.

41. Slezak-Prochazka I, Kluiver J, de Jong D, SmigielskaCzepiel K, Kortman G, Winkle M, Rutgers B, Koerts J, Visser L, Diepstra A, Kroesen BJ, van den Berg A. Inhibition of the miR-155 target NIAM phenocopies the growth promoting effect of miR-155 in B-cell lymphoma. Oncotarget. 2016;7:2391-2400. doi: 10.18632/oncotarget.6165.

42. Gan R, Yang Y, Yang X, Zhao L, Lu J, Meng QH. Downregulation of miR-221/222 enhances sensitivity of breast cancer cells to tamoxifen through upregulation of TIMP3. Cancer Gene Ther. 2014;21:290-296.

43. Cai Z, Cao R, Zhang K, Xue Y, Zhang C, Zhou Y, Zhou J, Sun H, Fu XD. Oncogenic miR-17/20a Forms a Positive Feed-forward Loop with the p53 Kinase DAPK3 to Promote Tumorigenesis. J Biol Chem. 2015;290:19967-19975.

44. Jin HY, Lai M, Xiao C. microRNA-17 92 is a powerful cancer driver and a therapeutic target. Cell Cycle. 2014;13:495-496.

45. Rao E, Jiang C, Ji M, Huang X, Iqbal J, Lenz G, Wright G, Staudt LM, Zhao Y, McKeithan TW, Chan WC, Fu $\mathrm{K}$. The miRNA-17 92 cluster mediates chemoresistance and enhances tumor growth in mantle celllymphoma via PI3K/AKT pathway activation. Leukemia. 2012;26:1064-1072.

46. Yang X, Du WW, Li H, Liu F, Khorshidi A, Rutnam ZJ, Yang BB. Both mature miR-17-5p and passenger strand miR-17-3p target TIMP3 and induce prostate tumor growth and invasion. Nucleic Acids Res. 2013;41:9688-9704.

47. Labbaye $\mathrm{C}$, Testa $\mathrm{U}$. The emerging role of MIR-146A in the control of hematopoiesis, immune function and cancer. J Hematol Oncol. 2012;5:13. 